\title{
Luthers Leiden und die (Zahn-)Medizin
}

Ein menschlicher Schädel auf einer Geige, daneben drapiert der Gipsabdruck eines Gebisses - über Geschmack lässt sich streiten, aber ein Hingucker ist das Arrangement in jedem Fall. Exponate wie dieses zeigt das Dentalhistorische Museum im sächsischen Zschadraß - insgesamt mehr als eine halbe Million Ausstellungsstücke aus der Geschichte der Zahnmedizin. Und zum 500. Jubiläum der Reformation gibt es eine Sonderausstellung: „Luthers Leiden und die Medizin im 16. Jahrhundert, Aufbruch in die Moderne."

Die Schau zeigt, dass die Medizin zur Zeit Luthers in die Moderne der (Zahn-)Medizin überging: Neue wissenschaftliche Erkenntnisse kamen zum alten medizinischen Wissen hinzu.

Holzschnitte, Schriftstücke, Instrumente und Objekte aus dem 16. Jahrhundert zeigen, inwieweit die frühen zahnmedizinischen Errungenschaften noch heutige Behandlungsmethoden prägen.

Highlights des Museums: Das Behandlungszimmer aus dem Film „Die Buddenbrocks“ und das wohl älteste Behandlungszimmer der Welt von 1750, nachgebildet vom Museumsgründer, Zahntechniker Andreas Haesler. Sonderausstellung vom 1. September 2017 bis 30. November 2017. Infos unter www.dentalmuseum.eu.

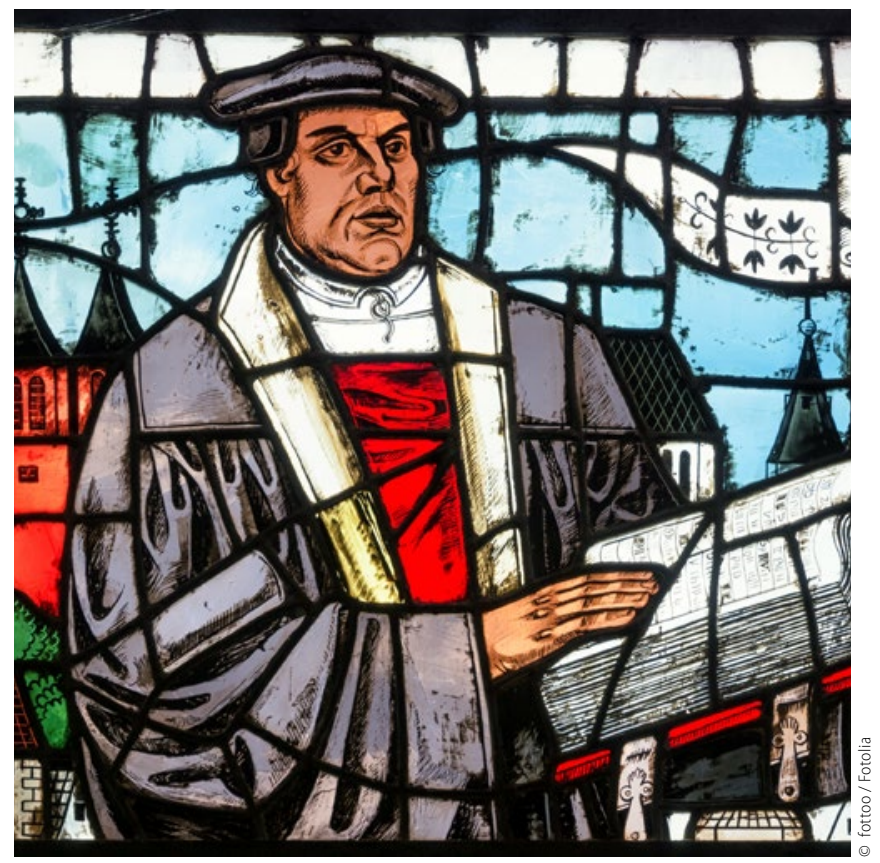

\section{Personalie}

\section{Mark Stephan Pace neuer VDDI-Chef}

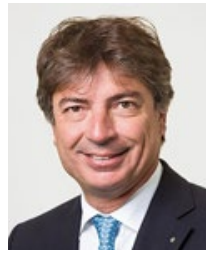

Neuer Vorstandsvorsitzender des Verbandes der Deutschen Dentalindustrie (VDDI) ist Mark Stephen Pace, Geschäftsführer Dentaurum GmbH \& Co KG in Ispringen. Die VDDI-Mitgliederver- sammlung wählte ihn am 27. Juni 2017 in Köln zum neuen Vorstandsvorsitzenden. Pace gehört dem Beirat des VDDI seit 2005 an, stellvertretender Vorsitzender war er seit 2013.

Jetzt schon vormerken!

\section{Nächstes „young dentists meeting“ im September}

Ende September steht das nächste „young dentists meeting" an. Am 29. und 30. September treffen sich wieder Berufseinsteiger in Bonn, um in entspannter Atmosphäre wichtige Infos und Tipps für den Praxisalltag zu bekommen. Wie immer gibt es am ersten Tag eine betriebswirtschaftliche Fortbildung und am zweiten Tag eine wissenschaftliche. Nähere Infos unter www.young-dentists.de.

red

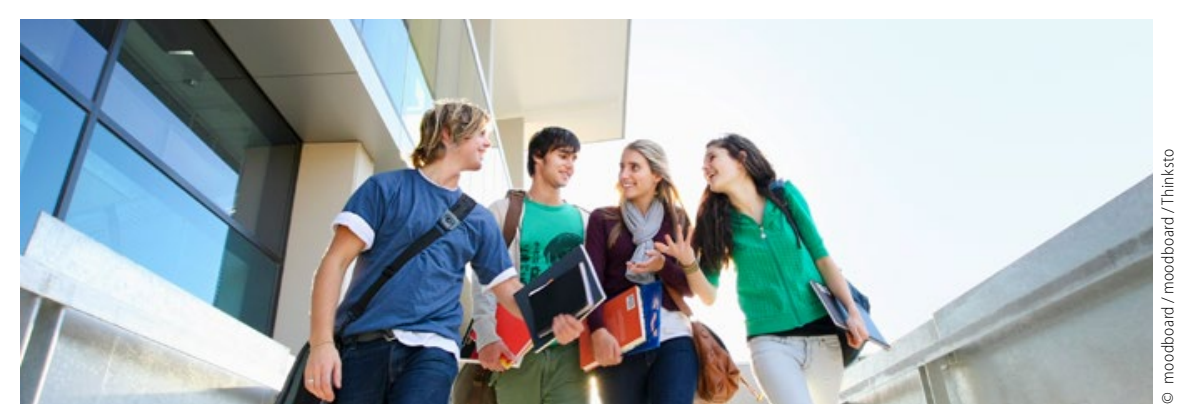

